\title{
Integrating MRS data with hydrologic model - Carrizal Catchment (Spain)
}

\section{G. Baroncini-Turricchia ${ }^{1,2, *}$, A.P. Francés ${ }^{1}$, M.W. Lubczynski ${ }^{1}$,}

\author{
J. Martínez-Fernández ${ }^{2}$ and J. Roy ${ }^{3}$
}

${ }^{1}$ ITC-Twente University, Hengelosestraat 99, Enschede, The Netherlands

${ }^{2}$ CIALE-Universidad de Salamanca, Calle Duero 1237185 Villamayor, Salamanca, Spain

${ }^{3}$ IGP, cp 48671 csp van Horne, Outremont, QC, Canada H2V 4T9, former ITC

Received February 2013, revision accepted January 2014

\begin{abstract}
Magnetic resonance sounding (MRS) provides quantitative hydrogeological information on hydrostratigraphy and hydraulic parameters of subsurface (e.g., flow and storage property of aquifers) that can be integrated in distributed hydrologic models. The hydraulic parameters are typically obtained by pumping tests. In this study, we propose an MRS integration method based on optimizing MRS estimates of aquifer hydraulic parameters through hydrologic model calibration.

The proposed MRS integration method was applied in the $73 \mathrm{~km}^{2}$ Carrizal Catchment in Spain, characterized by a shallow unconfined aquifer with an unknown aquifer bottom. 12 MRS survey results were inverted with Samovar 11.3, schematized and integrated in the transient, distributed, coupled, hydrologic, MARMITES-MODFLOW model. As the aquifer bottom was unknown, the aquifer was schematized into one unconfined layer of uniform thickness. For that layer, MRS estimators of specific yield and transmissivity/hydraulic conductivity were calculated as weighted averages of the inverted MRS layers. The MRS integration with hydrologic model was carried out by introducing multipliers of specific yield and transmissivity/hydraulic conductivity that were optimized during transient model calibration using 11 time-series piezometric observation points. The optimized multipliers were 1.0 for specific yield and $3.5^{*} 10^{-9}$ for hydraulic conductivity. These multipliers were used, and can be used in future MRS investigations in the Carrizal Catchment (and/or adjacent area with similar hydrogeological conditions), to convert MRS survey results into aquifer hydraulic parameters.

The proposed method of MRS data integration in the hydrologic model of Carrizal Catchment not only allowed us to calibrate the model but also to confirm the functional capability of MRS in quantitative groundwater assessment. Most importantly however, it demonstrated that if pumping tests are not available, the use of MRS integrated in distributed coupled hydrological models, or even in standalone groundwater models, provides a valuable aquifer parameterization alternative.
\end{abstract}

\section{INTRODUCTION}

In the last decades groundwater became widely used for water supply because of its better quality so lower treatment costs as compared to surface water and because of reduction of water abstraction cost (Llamas and Martínez-Santos 2005). However the prospection and quantification of groundwater is difficult due to subsurface heterogeneity. An improvement in the efficiency of evaluation and management of groundwater resources is needed to mitigate the increasing pressure of the demand, particularly in arid and semi-arid water limited environments.

For quantification of groundwater resources at the catchment scale, distributed numerical hydrological models are considered

*coprolog@yahoo.com optimal. However, to provide a valuable management tool, such models need appropriate acquisition of reliable spatial and temporal input data (Lubczynski 2011, Lubczynski and Gurwin 2005). A classic way to gather subsurface parameters to set up hydrological models is through borehole drilling and pumping tests. However, that method is invasive, expensive and time consuming. Non-invasive hydrogeophysical methods allow to complement the invasive methods, in an efficient and economically sound way. The application of such methods as a support for catchment scale, distributed hydrogeological models has recently received significant attention (Frances and Lubczynski 2011, Mahmoudzadeh et al. 2012). Dam and Christensen (2003) demonstrated that an improvement of the hydraulic conductivity field is possible using non-invasive techniques but depends on num- 